\title{
Gambaran Glaukoma Pada Pasien Diabetes Mellitus di RSUP Dr. M. Djamil Padang
}

\author{
Muhammad Fadhil ${ }^{1}$, M. Hidayat ${ }^{2}$, Fitratul Illahi ${ }^{3}$
}

\begin{abstract}
Abstrak
Diperkirakan pada tahun 2035, penderita diabetes mellitus akan meningkat menjadi 592 juta orang dari tahun 2013 yang jumlahnya diperkirakan 382 juta orang. Diabetes mellitus memiliki komplikasi makrovaskular dan mikrovaskular. Komplikasi mikrovaskular dapat berupa neuropati, pada mata seperti retinopati diabetikum, macular edem, katarak, dan glaukoma. Penelitian ini bertujuan untuk mengetahui gambaran glaukoma pada pasien diabetes mellitus di RSUP Dr. M. Djamil Padang.Penelitian ini merupakan penelitian dekstriptif retrospektif yang dilakukan pada Maret 2018 - April 2018. Sampel penelitian sebanyak 35 pasien yang memenuhi kriteria inklusi yang diambil secara total sampling. Data pasien didapatkan dari data rekam medis pasien di instalasi rekam medis RSUP Dr. M. Djamil Padang.Hasil penelitian ini menunjukan glaukoma pada pasien diabetes mellitus paling banyak pada jenis kelamin lakilaki $(65,7 \%)$. Untuk usia, glaukoma pada pasien diabetes mellitus paling banyak terjadi pada kelompok usia 40-60 tahun $(71,4 \%)$, sedangkan untuk jenis diabetesnya didapatkan pada diabetes tipe II dengan menderita DM $>5$ tahun. Jenis glaukoma pada pasien diabetes mellitus terbanyak adalah glaukoma sekunder. Perlu dilakukan studi epidemiologi lebih lanjut agar hasil lebih representatif.
\end{abstract}

Kata kunci: glaukoma, diabetes mellitus, mikrovaskular

\section{Abstract}

Based on prediction in 2035, the patients with diabetes will numbery increase to five hundred and twenty-nine million people from 2013 at the number three hundred and eighty-two people. Diabetes mellitus has macrovascular and microvascular complications. Microvascular complication can be neuropathy, in eyes such as diabetic retinopathy, macular edema, cataracts, and glaucoma. This research was aimed to find out an overview of glaucoma in patients with diabetes mellitus in RSUP Dr. M. Djamil Padang. This Research was descriptive study using retrospective approach, conducted in March 2018 - April 2018. The sample of study were thirty-five patients suited by inclusion criteria with total sampling method. Data was collected by evaluation medical records at Medical Records Department in RSUP Dr. M. Djamil Padang. The study showed glaucoma in patients with diabetes mellitus mostly in male gender (65.7\%). For ages, glaucoma in patients with diabetes mellitus most prevalent in the age group 40-60 years (71.4\%), while for the type of diabetes was found in type II diabetes with $D M>5$ years. The type of glaucoma in patients with diabetes mellitus mostly is secondary glaucoma. Further epidemiological studies are needed in order for more representative results.

Keywords: glaucoma, diabetes mellitus, microvascular

Affiliasi penulis: 1. Profesi Dokter FK UNAND (Fakultas Kedokteran Universitas Andalas Padang), 2. Bagian Mata FK UNAND/RSUP Dr. M. Djamil Padang, 3. Bagian Mata FK UNAND/RSUP Dr. M. Djamil Padang

Korespondensi: Muhammad Fadhil, email: m.fadhilfdl@gmail.com Telp: 082170099883

\section{PENDAHULUAN}

Menurut data International Diabetes Federation (IDF), diperkirakan terdapat 382 juta orang yang hidup dengan diabetes di dunia pada tahun 2013, diprediksikan angka tersebut akan terus bertambah pada tahun 2035 menjadi 592 juta orang. Dari 382 juta orang dengan diabetes tersebut, 175 juta diantaranya belum terdiagnosis, sehingga terancam berkembang menjadi progresif menjadi komplikasi tanpa disadari dan tanpa pencegahan. ${ }^{1}$

Di Indonesia, menurut IDF terdapat sebesar 9,1 juta penyandang DM tahun 2014 yang akan diperkirakan tahun 2035 bertambah menjadi 14,1 juta 
orang. Dengan berdasarkan data tersebut, tahun 2014 Indonesia menduduki peringkat ke-5 dunia untuk pengidap diabetes mellitus. ${ }^{2}$ Di samping prevalensinya yang semakin bertambah, penyakit DM akan semakin sulit bila telah terjadi komplikasi makrovaskular dan mikrovaskular. Komplikasi makrovaskular berupa penyakit jantung, hipertensi, stroke ataupun disfungsi ginjal. Sementara komplikasi mikrovaskular dapat berupa neuropati, serta pada mata seperti retinopati diabetikum, makular edema, katarak dan glaukoma. 3,4

Diketahui bahwa komplikasi mikrovaskular ini akan mempengaruhi autoregulasi dari retina dan saraf mata, hal tersebut akan menyebabkan kerusalan vaskularisasi mata sehingga mengakibatkan aliran darah ke mata berkurang dan disfungsi oksigen mata terganggu yang mengakibatkan terjadinya hipoksia realtif pada mata. Hipoksia realtif akan mengakibatkan kerusakan pada ganglion saraf serta serat saraf optic yang diakibatkan oleh hilangnya mekanisme autoregulasi mata terhadap fluktuasi TIO (Tekanan Intra Okular) dan aliran darah ke mata. Abnormalitas vascular mata pada DM ini akan meningkatkan kerentanan retina terhadap stress tambahan terkait glaukoma sudut terbuka atau peningkatan TIO.5,6 DM yang mempunyai komplikasi retinopati diabetikum, dikenal juga klasifikasi retinopati diabetikum non ploriperatif dan retinopati diabetikum ploriperatif, diamna retinopati diabetikum ploriperatif dapat menyebabkan glaukoma neovaskular. Sekitar $21 \%$ dari keseluruhan kasus retinopati diabetikum menyebabkan glaukoma neovaskular dengan frekuensi terbentuknya rubeoisis iridis sekitar $65 \% .^{7,8}$

Glaukoma merupakan penyebab kebutaan kedua di seluruh dunia, dengan morbiditas yang tidak proporsional diantara wanita dan orang asia. ${ }^{9}$ Berbeda dengan katarak, glaukoma merupakan penyakit mata yang mengakibatkan kerusakan permanen atau bersifat tidak dapat diperbaiki (Irreversible). Menurut WHO terdapat sekitar 60,7 juta orang menderita glaukoma tahun 2010 yang dimana diperkirakan tahun 2020 akan menjadi 79,4 juta orang. ${ }^{10}$

Penelitian di poliklinik Mata BLU RSUP Prof. Dr. R. D Kandou Manado tahun 2013 didapatkan 15 pasien glaukoma akibat DM, dimana terdapat 12 pasien (80\%) dari poliklinik mata dan 3 pasien $(20 \%)$ dari data rawat inap. Berdasarkan jenis kelamin, didapatkan perempuan 10 orang $(66,7 \%)$ dan laki - laki 5 orang $(33,3 \%)$ sedangkan berdasarkan kelompok umur 40 60 tahun sebanak 7 pasien $(46,6 \%)$ dan $>60$ tahun sebanyak 8 pasien $(53,4 \%)$. Berdasarkan tipe DM yang mengakibatkan glaukoma, DM tipe II lebih banyak dengan 14 orang $(93,3 \%)$ dibanding DM tipe I 1 orang $(6,7 \%)$. Sedangkan distribusi berdsarkan DM terkontrol dan tidak terkontrol didapati DM terkontrol sebanyak 3 orang $(20 \%)$ dan tidak terkontrol sebanyak 12 orang $(80 \%){ }^{3}$

\section{METODE}

Jenis penelitian ini adalah dekskriptif retrospektif dimana variabel penelitiannya adalah jenis kelamin, usia, jenis DM, lama menderita DM dan jenis glaukoma.Penelitian dilakukan dari bulan Maret-April 2018 di Bagian Rekam Medis RSUP Dr. M. Djamil Padang, Sumatera Barat.

Populasi penelitian ini adalah penderita yang didiagnosis diabetes mellitus dengan terdapat riwayat glaukomayang tercatat pada rekam medis Januari 2016 - September 2017. Sampel penelitian yang dipilih adalah penderita yang didiagnosis diabetes mellitus dengan riwayat glaukoma yang memenuhi kriteria inklusi dan kriteria eksklusi. Kriteria inklusi subjek: jenis kelamin, usia, jenis DM, lama menderita DM, jenis glaukoma. Kriteria eksklusi subjek: tidak terdapat diagnose di dalam rekam medis dan diagnose diabetes mellitus dengan riwayat glakoma meragukan.

Data diperoleh dengan cara memeriksa data sekunder melalui data rekam medis yang terdapat di bagian rekam medis RSUP Dr. M. Djamil Padang. Data dianalisis secara statistik berdasarkan variabel yang dinilai menggunakan sistem komputerisasi yaitu analisis univariat. Analisis univariat dilakukan untuk melihat distribusi frekuensi dari masing-masing variabel yang diteliti yaitu distribusi berdasarkan jenis kelamin, usia, riwayat DM penderita dan jenis glaukoma pada pasien diabetes mellits di RSUP Dr. M. Djamil Padang tahun $2016-2017$.

\section{HASIL}

Penelitian ini dilakukan di Bagian Rekam Medis RSUP Dr. M. Djamil padang bulan Maret - April 2018, didapatkan jumlah pasien Glaukoma pada pasien Diabetes Mellits pada tahun 2016-2017 adalah 35 pasien yang memenuhi kriteria inklusi. 
Tabel 1. Distribusi frekuensi glaukoma pada pasien DM berdasarkan jenis kelamin di RSUP Dr. M. Djamil Padang

\begin{tabular}{ccc}
\hline Jenis Kelamin & $f$ & $\%$ \\
\hline Laki - Laki & 23 & 65,7 \\
Perempuan & 12 & 34,3 \\
\hline Total & 35 & 100,0 \\
\hline
\end{tabular}

Berdasarkan tabel 1 dapat dilihat bahwa frekuensi glaukoma pada pasien diabetes mellitus di RSUP Dr. M. Djamil Padang berdasarkan jenis kelamin adalah terdapat 23 pasien berjenis kelamin laki - laki $(65,7 \%)$ dan 12 pasien perempuan $(34,3 \%)$.

Tabel 2. Distribusi frekuensi glaukoma pada pasien DM berdasarkan usia di RSUP Dr. M. Djamil Padang

\begin{tabular}{ccc}
\hline Usia & $f$ & $\%$ \\
\hline$<40$ tahun & 0 & 0 \\
$40-60$ tahun & 25 & 71,4 \\
$>60$ tahun & 10 & 28,6 \\
\hline Total & 35 & 100,0 \\
\hline
\end{tabular}

Pada tabel 2 didapatkan bahwa fistribusi frekuensi glaukoma pada pasien diabetes mellitus di RSUP Dr. M. Djamil Padang berdasarkan kelompok usia terbanyak pada kelompok usia 40 - 60 tahun yaitu sebanyak 25 pasien $(71,4 \%)$, disusul kelompok usia $>60$ tahun 10 pasien $(28,6 \%)$.

Tabel 3. Distribusi frekuensiglaukoma pada pasien DM berdasarkan Jenis DM di RSUP Dr. M. Djamil Padang

\begin{tabular}{ccc}
\hline Jenis DM & $f$ & $\%$ \\
\hline DM Tipe I & 0 & 0 \\
DM Tipe II & 35 & 100,0 \\
\hline Total & 35 & 100,0 \\
\hline
\end{tabular}

Berdasarkan tabel 3 distribusi glaukoma pada pasien diabetes mellitus berdasarjan jenis DM pada penelitian ini didapatkan semua pasien glaukoma berjenis DM Tipe 2 sebanyak 35 pasien (100\%).

Tabel 4. Distribusi frekuensi glaukoma pada pasien DM berdasarkan lama menderita DM di RSUP Dr. M. Djamil Padang

\begin{tabular}{ccc}
\hline Lama Menderita DM & $f$ & $\%$ \\
\hline$<5$ tahun & 0 & 0 \\
$>5$ tahun & 35 & 100,0 \\
\hline Total & 35 & 100,0 \\
\hline
\end{tabular}

Berdasarkan tabel 4 pada penelitian ini didapatkan bahwa semua pasien glaukoma menderita diabetes mellitus $>5$ tahun sebanyak 35 pasien (100\%).
Tabel 5. Distribusi frekuensi glaukoma pada pasien DM berdasarkan jenis glaukoma di RSUP Dr. M. Djamil Padang

\begin{tabular}{lcc}
\hline \multicolumn{1}{c}{ Jenis Glaukoma } & $f$ & $\%$ \\
\hline $\begin{array}{l}\text { Glaukoma Primer Sudut } \\
\text { Terbuka }\end{array}$ & 4 & 11,4 \\
Glaukoma Primer Sudut & 0 & 0 \\
Tertutup & 6 & 17,1 \\
Glaukoma Normotension & 25 & 71,4 \\
Glaukoma Sekunder & 35 & 100,0 \\
\hline \multicolumn{1}{c}{ Total } &
\end{tabular}

Berdasarkan tabel 5 didapatkan bahwa pada penelitian ini distribusi frekuensi glaukoma pada pasien DM berdasarkan jenis glaukoma di RSUP Dr. M. Djamil Padang adalah paling banyak pada glaukoma sekunder dengan 25 pasien $(71,4 \%)$, lalu disusul oleh glaukoma normotension 6 pasien $(17,1 \%)$ dan glaukoma primer sudut terbuka 4 pasien $(11,4 \%)$.

\section{PEMBAHASAN}

Berdasarkan hasil penelitian deskriptif retrospektif tentang glaukoma pada pasien diabetes mellitus di RSUP Dr. M. Djamil padang tahun 20162017 didapatkan jumlah laki-laki lebih banyak menderita glaukoma dari pada perempuan (tabel 1), hal itu kemungkinan disebabkan karena kebiasaan berobat pada pasien diabetes mellitus berbeda antara laki - laki dan perempuan. Laki-laki dikatakan memiliki kecenderungan untuk tidak patuh dalam melakukan tes gula darah secara berkala dibangkingkan perempuan. Laki-laki juga dikatakan dalam penelitian tersebut lebih pasif dibandingkan perempuan dalam control dan perawatan diabetes tersebut, sehingga ini meningkatkan resiko tinggi untuk terjadinya glaukoma pada pasien laki-laki. ${ }^{11}$

Pada penlitian ini, ditemukan kelompok usia 4060 tahun yang terbanyak menderita glaukoma pada pasien diabetes mellitus. Faktor yang didketahui beresiko memicu dan memperburuk glaukoma antara lain adalah umur mulai 40 tahun, keluarga yang mempunyai riwayat glaukoma, myopia, hypermetropia, mengidap penyakit diabetes mellitus, hipertensi, vasospasme, migren, pengguna kotrikostreoid, obstruki vena retina sentral, trauma, radang dan operasi mata. ${ }^{3,12}$ Pada kelompok umur $>40$ tahun dijelaskan bahwa aliran aqueous humor akan berkurang sebanyak $30 \%$ selama hidup dan menyebabkan peningkatan TIO. Pada umur $>70$ tahun dikatakan lebih beresiko 3 sampai 8 kali untuk terkena glaukoma sudut terbuka primer, untuk glaukoma sudut tertutup primer sendiri 
lebih di dominasi oleh kelompok umur sekitar 55 sampai 65 tahun. ${ }^{12}$

Berdasarkan tipe DM pada tabel 3, semua pasien glaukoma yang ditemukan pada penelitian ini adalah DM tipe II. Untuk DM, baik tipe I ataupun DM tipe II keduanya merupakan faktor resiko untuk terkena komplikasi retinopati diabetikum, katarak, maupun glaukoma. ${ }^{3,4,5}$ DM akan mengakibatkan nerodegenerasi dimana hal tersebut akan menyebabkan peningkatan stress oksidatif pada sel mata yang mengakiatkan vaskulirasinya terganggu dan difusi oksigen sel - sel mata juga terganggu. Hal tersebut menyebabkan kerusakan sel glial dan sel endotel mata yang mengakibatkan hipoksia pada sel mata sehingga menyebabkan perubahan pada anatomi dan fungsi saraf mata. DM tipe II menyebabkan penipisan RNFL (Renal Nerve Fibre Layer) lebih awal daripada orang yang tidak menderita diabetes sehingga beresiko tinggi untuk terjadinya glaukoma. 6,13

Pada tabel 4, semua pasien glaukoma pada penelitian ini menderita $\mathrm{DM}>5$ tahun. Zhao meneliti durasi penderita DM dengan hubungan tingginya resiko glaukoma, didapatkan bahwa semakin lama durasi seseorang terkena diabetes mellitus maka akan terjadi kerusakan yang lebih lama terhadap sel glial mata dan fungsi neural mata yang akan mengakibatkan resiko tinggi untuk menjadi glaukoma. ${ }^{5}$

Jenis glaukoma yang ditemukan pada penelitian ini paling banyak adalah glaukoma sekunder. Diantara 25 pasien glaukoma sekunder, 14 pasien menderita glaukoma sekunder neovaskular dari 35 sampel (40\%). DM merupakan faktor presdiposisi yang menyabkan komplikasi mikrovaskular ini, baik yang didahului oleh adanya retinopati diabetic terlebih dahulu ataupun yang telah terdiagnosis glaukoma pada pasien DM tersebut, hal itu sesuai dengan penelitian yang dilaksanakan di King Khaled Eye Hospital Saudi Arabia. Retinopati diabetikum mengkaibatkan iskemik pada mata akibat terganggunya vaskularisasi mata yang akan menyebabkan neovaskularisasi yang berujung glaukoma neovaskular. ${ }^{8}$

Untuk 6 orang pasien glaukoma normotension, selain mempunyai riwayat DM dengan glaukoma, juga disertai penyakit lain seperti hipertensi yang beresiko tinggi menjadi faktor presdiposisi glaukoma normotension ini. Hal tersebut telah dibuktikan oleh
Kenji dengan membandingkan TIO dengan subjek yang terdiagnosis DM juga hipertensi, baik dengan retinopati atau tidak dengan retinopati dimana menunjukkan hasil yang signifikan untuk hasil tes TIO-nya yang beresiko tinggi untuk terjadi glaukoma normotension. ${ }^{14}$ Sedangkan 4 orang pasien dengan glaukoma sudut terbuka primer, Zhao meneliti hubungan DM denga kejadian glaukoma sudut terbuka primer. Ditemukannya hubungan yang signifikan, dimana hal tersebut diakibatkan oleh mekanisme kerusakan mikrovaskular mata yang merusak sel glial dan sel neural mata sehinga akan tingginya terjadi resiko penignkatan TIO dan terjadinya glaukoma sudut terbuka primer. ${ }^{5,6}$

\section{SIMPULAN}

Berdasarkan hasil penelitian ini didapatkan kesimpulanbahwa penderita glaukoma lebih banyak pada jenis kelamin laki-laki, dimana kelompok usia terbayak 40-60 tahun dan semua pasien glaukoma berjenis DM tipe II dengan durasi DM $>5$ tahun. Jenis glaukoma yang paling banyak ditemukan adalah glaukoma sekunder.

\section{DAFTAR PUSTAKA}

1. Kementrian Kesehatan RI. Situasi dan Analisis Diabetes. Pusat Data dan Informasi Kesehatan RI 2014:1-7

2. Persatuan Endokrinologi Indonesia. Konsensus Pengendalian dan Pencegahan Dlbaetes Mellitus Tipe 2 di Indonesia 2015. Jakarta: Perkeni; 2015.

3. Allorerrung R, Saerang JS, Rares L. Prevalensi Glaukoma Akibat Diabetes Mellits di Poliklinik Mata RSUP Prof. Dr. R. D. Kandou Manado. Jurnal eClinic. 2015; 3:3-6.

4. Aiello LP, Alejandro R, Alsahli M, Atkinson MA, Bode BW, Skyler JS, editor. Atlas of Diabetes Fourth. Miami; 2012. 249-275.

5. Zhao D, Cho J, Kim MH, Friedman DS, Guallar E. Diabetes, Fasting Glucose and The Risk of Glaucoma: A meta-analysis. Opthamology. 2015; 122(1):72-8.

6. Wong VHY, Bui BV, Vingrys AJ. Clinical and Experimental Links Between Diabetes and Glaucoma. Clinical and Experimental Optometry. 2011; 94(1):4-23. 
7. Palma C, Kim D, Singh AD, Sing A. Neovascular Glaucoma. Second Ed. Elsevier Ltd. 2015; 425433.

8. Al-Bahlal A, Kahndekar R, Al-Rubei K, Alzahim T, EdwardPD, Kozak L. Changing Epidemiology of Neovascular Glaucoma from 2002-2012 at King Khaled Eye Specialist Hospital Saudi Arabia. Indian J Ophthalmol. 2017; 65(10):969-71.

9. Stamper RL, Liberman MF, Drake MV. BeckerShaffer's Diagnosis and Therapy of the Glaucomas. $8^{\text {th }}$ Ed. Elsevier Inc. 2009: 1-560.

10. Kementrian Kesehatan RI. Situasi dan Analisis Glaukoma. 2015: 1-6.

11. Fitzgerald JT, Anderson RM, Davis WK. Gender Differences in Diabetes Attitudes and Adherence. The Diabetes Educator. 1995; 21(6):523-9.

12. American Academy of Opthamology. 2016-2017 Basic and Clinical Science Course, Section 10: Glaucoma. 2016: 20-192.

13. Press Dove. Follow-up of The Retinal Nerve Fiber Layer Thickness of Diabetic Patients Type 2, as A Presdiposising Factor for Glaucoma Compared to Normal Subjects. Clinical Opthamology. 2017; 1135-1141.

14. Sakata K, Matsumoto L, Oyamaguchi EK, Carvalho AA, Knoblauch N, Gil A, et al. Analysis of The Intraocular Pressure in Diabetic, Hypertensive and Normal Patients (Glaucoma Project). Scientific Electronic Libray Online. 2000; 63:223-226. 